\title{
Accumulation mode particles and LPS exposure induce TLR-4 dependent and independent inflammatory responses in the lung
}

Angela M. Fonceca ${ }^{1 *}$, Graeme R. Zosky², Elizabeth M. Bozanich², Erika N. Sutanto 2,3, Anthony Kicic 1,2,3,4, Paul S. McNamara ${ }^{5}$, Darryl A. Knightt ${ }^{6,7,8}$, Peter D. Sly ${ }^{9}$, Debra J. Turner ${ }^{2}$ and Stephen M. Stick ${ }^{1,2,3,4}$

\begin{abstract}
Background: Accumulation mode particles (AMP) are formed from engine combustion and make up the inhalable vapour cloud of ambient particulate matter pollution. Their small size facilitates dispersal and subsequent exposure far from their original source, as well as the ability to penetrate alveolar spaces and capillary walls of the lung when inhaled. A significant immuno-stimulatory component of AMP is lipopolysaccharide (LPS), a product of Gram negative bacteria breakdown. As LPS is implicated in the onset and exacerbation of asthma, the presence or absence of LPS in ambient particulate matter (PM) may explain the onset of asthmatic exacerbations to PM exposure.

This study aimed to delineate the effects of LPS and AMP on airway inflammation, and potential contribution to airways disease by measuring airway inflammatory responses induced via activation of the LPS cellular receptor, Toll-like receptor 4 (TLR-4).
\end{abstract}

Methods: The effects of nebulized AMP, LPS and AMP administered with LPS on lung function, cellular inflammatory infiltrate and cytokine responses were compared between wildtype mice and mice not expressing TLR-4.

Results: The presence of LPS administered with AMP appeared to drive elevated airway resistance and sensitivity via TLR-4. Augmented TLR4 driven eosinophilia and greater TNF-a responses observed in AMP-LPS treated mice independent of TLR-4 expression, suggests activation of allergic responses by TLR4 and non-TLR4 pathways larger than those induced by LPS administered alone. Treatment with AMP induced macrophage recruitment independent of TLR-4 expression.

Conclusions: These findings suggest AMP-LPS as a stronger stimulus for allergic inflammation in the airways then LPS alone.

Keywords: Asthma, TLR-4, PM, LPS, AMP, COPD

\section{Background}

Exposure to ambient air pollution is an adverse health risk to respiratory health, particularly in the young, elderly and those with co-morbidities such as heart disease $[1,2]$. In the young, epidemiological and toxicological research studies consistently demonstrate air pollution as a major risk factor in the onset of asthma [3, 4]. This

\footnotetext{
* Correspondence: angela.fonceca@uwa.edu.au

'School of Paediatrics and Child Health, University of Western Australia, Nedlands, WA, Australia

Full list of author information is available at the end of the article
}

is well illustrated by rising rates of asthma observed in developing countries such as China where expanding industrialization correlates with raised airborne pollution [1]. While in the elderly, long term exposure to particulate matter $(\mathrm{PM})$ has been implicated in developing COPD $[1,2,5,6]$. Not surprisingly, hospital admission rates for breathing difficulties have been shown to rise during times of raised ambient air pollution concentrations [3]. Despite the risks of air pollution exposure being well accepted, the precise mechanisms leading to the onset of these chronic airway diseases are poorly understood [6-9]. 
Ambient air pollution, comprised in part by AMP, is a complex mixture of organic compounds, different sized particles and chemicals [10]. The US EPA refers to the inhalable solid phase of ambient air pollution as PM categorized as; coarse $(\leq 10 \mu \mathrm{m})$, fine $(\leq 2.5 \mu \mathrm{m})$ and ultrafine $(\leq 0.1 \mu \mathrm{m})$ [11]. Accumulation mode particles (AMP) straddle the ultrafine particulate (UFP) and fine categories making up the inhalable vapour cloud of PM [12]. AMP's are largely sourced from engine combustion. Due to their small size these are subject to wind and other climatic conditions which enable dispersal and exposure far from their source of origin [13]. As AMP are small enough to penetrate alveolar spaces and capillary walls, exposure to this particulate size fraction has been shown to result in respiratory disease and exacerbation, with exposure also linked to cardiovascular disease $[12,13]$.

To date, the majority of air pollution toxicology studies have explored the role of whole ambient mixtures and individual chemical components on respiratory health [7-9]. Due to the number of stimuli within ambient air, identifying the causes and/or interactions responsible for the onset of disease is difficult, as these can trigger a variety of host defence mechanisms when inhaled [14-16]. Oxidative particulates and/or reactive oxygen species generated by particulate phagocytosis have been shown to drive proinflammatory pathways which can cause long-term lung damage and airway disease [17-19]. There is also evidence to suggest Toll like receptor (TLR)-2 and TLR-4 activation in these PM driven inflammatory processes as part of an inflammasome driven response [20-23].

The TLR family are well described pattern recognition receptors that detect characteristic microbial motifs to signal the presence of invading microbial organisms [24]. TLR function forms part of the innate immune system and induce pro-inflammatory cytokine release. These signals alert and activate surrounding tissues and the adaptive immune system [24]. Bacteria are detected by TLR-2 and TLR-4 which recognise components of Gram positive and Gram negative bacterial cell walls known as lipotoeic acid (LTA) and lipopolysaccharide (LPS, also known as endotoxin) respectively [24]. Recognition of either LTA and LPS by TLR's induces a cascading inflammatory response which can be severe as in the case of sepsis when bacteria are found in blood [25].

Both LTA and LPS form a significant immunostimulatory component of ambient air. This has been shown by reduced inflammatory responses in cell cultures treated with ambient PM preparations mixed with polymixin B, a compound binding the Lipid A moiety of LPS [26]. While exposure to LPS has been shown to exacerbate asthma there is conflicting evidence to suggest it also modulates allergic airway responses [27, 28]. The role of TLR-2 and TLR-4 in responses to ambient PM has been further elucidated in alveolar macrophages, a key phagocyte in the lung [29]. However, the overall effects of LPS and PM (including AMP) deposited in the lower airways and the impact of this on lung function and immune modulation has not been fully investigated.

In this study we aimed to delineate the individual and combined effects of LPS and AMP on airway inflammation and potential contribution to airway disease. Due to the well documented inflammatory effects of LPS, we hypothesized that airway inflammation induced by exposure to AMP would be augmented when AMP was coadministrated with LPS. Using a mouse model, the inhaled effects of nebulised AMP, LPS and AMP administered together with LPS on lung function, inflammatory cell infiltrate and cytokine responses in bronchoalveolar lavage and lung parenchymal tissue. To determine the role of TLR-4 in AMP and LPS induced airway inflammation, results were compared between wildtype mice and mice not expressing TLR-4. As PM size fractions contain a mixture of compounds which includes attached LPS [10, 30], an inert fluorescent bead model was used in order to clearly assess the impact of AMP delivered with a known amount of LPS attached.

\section{Methods}

\section{Animals}

We used commercially available fluorescent polystyrene beads as a model for inert AMP (Fluoresbrite ${ }^{\text {ts }}$ polychromatic red microspheres, Polysciences Inc., Pennsylvania, USA; herein referred to as AMP) exposure as has been used previously [31]. In this study, mice with a mutated non-functional TLR-4 expression $(\mathrm{C} 3 \mathrm{H} / \mathrm{HeJ}$, referred to as TLR4-/-) and mice of the same strain expressing TLR-4 (C3H/HeN, referred to as wildtype, WT) were used in order to assess changes in respiratory mechanics and lung inflammation in response to nebulized treatments of AMP, LPS and a mixed AMP-LPS preparation. TLR4-/- mice have been previously characterized with dysfunctional TLR-4 expression due to a spontaneous proline to histidine point mutation in the TLR-4 signaling sequence [32]. This mouse model is commonly used as a negative control for TLR-4 expression in studies investigating TLR-4 responses [33, 34]. Mice were used at 7-9 weeks of age (Animal Resource Centre, Murdoch, Western Australia) and housed in a controlled environment with a $12 \mathrm{~h}$ light to dark cycle with unrestricted access to food and water. All experiments presented were approved by the Telethon Kids Institute's Animal Ethics Committee (approval reference \#128) and carried out in accordance with the recommendations of the Australian code for the care and use of animals for scientific purposes 8th edition (2013).

Ten mice of each strain were grouped to receive the following nebulized treatments: LPS alone $(50 \mu \mathrm{g} / \mathrm{ml}$, 
Salmonella typhimurium, Sigma-Aldrich, St. Louis, Missouri, USA); $0.5 \mu \mathrm{m}$ polystyrene beads alone $(50 \mu \mathrm{g} / \mathrm{ml}$, equating to approximately $7.26 \times 10^{10}$ particles $/ \mathrm{ml}$ of AMP; both AMP and LPS (AMP-LPS, $50 \mu \mathrm{g} / \mathrm{mL}$ ); or double-distilled water (control). Double distilled water and AMP nebulization preparations contained $<0.015$ $\mathrm{EU} / \mathrm{ml}$ (detection limit) using the Limulus amebocyte lysate (LAL) assay (Sigma-Aldrich, Missouri, USA). Double distilled water induced less airway resistance to methacholine at doses above $3 \mathrm{mg} / \mathrm{ml}$ during challenge compared to endotoxin free $0.9 \%$ saline, confirming suitability of this as a control for these studies (see Additional file 1: Figure S1) [35]. To best represent short term exposure inducing an inflammatory response, mice were exposed to their allocated treatment at constant flow of $3 \mathrm{ml} / \mathrm{min}$ for $30 \mathrm{~min}$ at the same time for six consecutive days. Nebulized aerosols were delivered to animals via an UltraNeb ${ }^{\text {Tx }}$ nebulizer (DeVilbiss, Somerset, Pennsylvania, USA), as described previously [36]. According to DeVilbiss, nebulized droplet size distribution generated ranges from $0.5-3 \mu \mathrm{m}$ [37]. As a solution of $0.5 \mu \mathrm{m}$ polychromatic spheres were used, the overall nebulization range was deemed to fit the accumulation mode particle size range $(0.1-2.5 \mu \mathrm{m})$ for the purposes of this study.

\section{Lung function measurements}

Lung function was assessed using a modification of the low frequency, forced oscillation technique (LFOT). Mice were initially anaesthetized with an intraperitoneal injection of a solution containing xylazine $(2 \mathrm{mg} / \mathrm{ml}$, Troy Laboratories, NSW, Australia) and ketamine (40 mg/ml, Troy Laboratories, NSW, Australia) at a dose of $0.01 \mathrm{mg} / \mathrm{g}$. Mice were then tracheotomized and a $10 \mathrm{~mm}$ section of polyethylene tubing $(1.27 \mathrm{~mm}$ OD, $0.86 \mathrm{~mm} \mathrm{ID}$ ) inserted into the trachea. Mice were ventilated at 450 breaths $/ \mathrm{min}$ with a tidal volume of $8 \mathrm{ml} / \mathrm{kg}$ and a positive end expiratory pressure (PEEP) of $2 \mathrm{~cm}$ $\mathrm{H}_{2} \mathrm{O}$ using a computer-controlled ventilator (flexiVent, SCIREQ Inc., Montreal, Canada). This system was used for ventilation and measurement of respiratory mechanics as previously described [38, 39].

Before commencing lung function measurements, mouse lung volume history was standardized using 5 deep inflations to total lung capacity. Respiratory impedance (Zrs) was measured using an oscillatory signal containing 19 frequencies ranging from 0.25 to $19.625 \mathrm{~Hz}$ during pauses in ventilation. Zrs was partitioned into components representing the mechanical properties of the airways and lung tissue parenchyma using a four parameter model with constant phase tissue impedance [38, 39]. Partitioning of Zrs in this way allows calculation of parameters representing airway resistance, tissue damping and tissue elastance [40, 41].

\section{Methacholine challenge}

Following measurement of baseline Zrs, mice were exposed to a saline aerosol for 90 s $^{(U l t r a n e b}{ }^{\text {tw }} 99$, Devilbiss, Somerset, Pennsylvania, USA). Five measurements of $\mathrm{Zrs}$ were then obtained, averaged and used as the control measurements for MCh challenge. The aerosol procedure was repeated with half log incremental doses of MCh from 0.1 to $30 \mathrm{mg} / \mathrm{ml}$. Measurements of Zrs were recorded every minute for $5 \mathrm{~min}$ after each $\mathrm{MCh}$ aerosol and the maximum response calculated. From these, data dose response curves for airway resistance (Raw) were constructed. Sensitivity to MCh was determined by calculating the MCh dose required to produce a $200 \%$ increase in Raw in response to the saline challenge at $30 \mathrm{mg} / \mathrm{ml}$ using interpolation [41]. Maximum responses in Raw and airway sensitivity were used to compare lung function responses between groups.

\section{Inflammatory cell counts}

Five additional animals per group were anaesthetised and tracheotomised for bronchoalveolar lavage (BAL) used for inflammatory cell infiltrate and inflammatory cytokines analysis as previously described [40]. Briefly, BAL fluid was collected by slowly infusing and withdrawing a $1 \mathrm{ml}$ aliquot of $0.9 \%$ saline from the lung three times. The resulting fluid was centrifuged at $2000 \mathrm{rpm}$ for $4 \mathrm{~min}$. Supernatant was collected and stored at $-80{ }^{\circ} \mathrm{C}$ for later analysis. The cell pellet was resuspended in saline and a portion stained with trypan blue to determine viability and total cell count (TCC). The remaining portion was centrifuged onto slides and stained with Leishman's (Sigma-Aldrich, St Louis, Missouri, USA) to obtain differential cell counts.

\section{Inflammatory cytokine responses Bronchoalveolar lavage (BAL)}

Analysis of BAL for the presence of secreted proinflammatory cytokines known to be secreted in response to LPS and PM [42]. Interleukin (IL)-6, Interferon (IFN)- $\gamma$, and Tumor necrosis factor (TNF)- $\alpha$ was completed using a cytokine bead array assay (BD Biosciences California, USA) as per manufacturers' instructions, with a detection range of $20-5000 \mathrm{pg} / \mathrm{ml}$ for all cytokines within the array. These measurements were completed in BAL from five mice of each mouse strain for each treatment using an optimized sample dilution factor.

\section{Lung parenchyma}

Soluble protein was extracted from a single mouse lung lobe to gain a measure of subepithelial pro-inflammatory responses indicative of airway remodelling and developing chronic airway inflammation. For this reason expression of immune-regulatory, IL-10 and pro-fibrotic cytokine, IL-13, were examined using ELISA (R\&D Systems, 
Abdington, UK; detection ranges: IL-10, 31.2-2000 pg/ml and IL-13, 62.5-4000 pg/ml) using optimised sample dilution factors. Specifically, IL-10 was chosen as it is secreted in response to LPS and is thought to protect the lung against lung injury by reducing the production of proinflammatory cytokines, chemokines and transcription factors implicated in airway remodelling. Whereas IL-13 is known to be involved in subepithelial fibrosis related to the onset of asthma and COPD. Data was calculated and normalized to $100 \mu \mathrm{g}$ of total soluble protein as measured using the Pierce BCA assay (Thermo-Pierce, Rockford, USA) for comparative purposes.

\section{Statistical analysis}

SPSS Levene's test was used to test for equal variance across all the groups of data compared. Following verification, an independent $\mathrm{t}$-test was then used to determine statistically significant differences between (a) controls and treatment groups and (b) single treatments between WT and TLR4-/- mice. Due to differences in baseline lung function (see results Table 1), responses to $\mathrm{MCh}$ were expressed as a percentage of baseline with graphs are shown as mean \pm SEM. Due to the range of data, cytokine responses are presented as box and whisper plots depicting interquartile range and 2.5 and 97.5 percentiles with medians. A minimum of 4 biological replicates and $p$ values $<0.05$ considered significantly different were used for all data sets.

\section{Results}

\section{Lung function}

Baseline lung function responses were recorded for each animal prior to saline and methacholine $(\mathrm{MCh})$ challenge (Table 1). Baseline airway resistance (Raw) values were elevated in all TLR4-/- mice compared to wildtype (WT) mice of the same treatment (PM $p=0.04$, LPS $p=0.03$, PM-LPS $p=0.035)$, including control mice $(p=0.035)$; indicating this mouse strain had more sensitive airways overall. However, baseline Raw did not vary considerably between mice of the same strain treated with AMP, LPS or AMP-LPS nebulisations (Table 1).

At $30 \mathrm{mg} / \mathrm{ml} \mathrm{MCh}$, Raw was significantly augmented in WT mice treated with nebulized LPS or AMP-LPS compared to control mice $(p=0.04$ and 0.03 respectively, Fig. 1a). Sensitivity to $\mathrm{MCh}$ as determined by interpolation, was significantly less in WT mice treated with LPS $(p=0.008)$ and AMP-LPS $(p=0.017)$ compared to controls. This was not observed in LPS and AMP-LPS treated TLR4-/- mice, indicating more sensitive airways in response to LPS and AMP-LPS treatments in the presence of TLR-4 (Fig. 1b). Responses for all other doses of MCh used for challenge can be found in Additional file 2: Figure S2.

\section{Cellular responses measured in bronchoalveolar lavage}

Bronchoalveolar lavage (BAL) inflammatory total cell counts were larger in WT mice treated with AMP, LPS ( $p$ $<0.001)$ and AMP-LPS $(p<0.001)$ compared to WT control mice. Total cell counts in WT mice treated with LPS $(p<0.001)$ and AMP-LPS $(p<0.001)$ were greater than similarly treated TLR4-/- mice (Fig. 2a). Neutrophils were the predominant cell type in LPS and AMP-LPS treated WT mice compared to control and AMP treated mice $(p<0.001)$ (Fig. 2b). In contrast, neutrophils were barely detectable in TLR4 -/- mice irrespective of exposure. Macrophages were the dominant cell type in mice treated with AMP irrespective of strain ( $p=0.01$ for both strains) and in TLR4-/- mice treated with LPS $(p=0.007)$ and AMP-LPS $(p=0.04)$ compared to respective controls (Fig. 2c). Eosinophil numbers were greater in WT mice treated with LPS $(p=0.006)$ and AMP-LPS $(p<0.001)$; for which numbers were larger in AMP-LPS treated mice $(p$ $=0.024)$ compared to those treated with LPS. Lymphocyte and epithelial cell numbers were not significantly different between controls and any of the treatments given for either strain. Other cytokine responses measured using the commercial kit can be found in Additional file 3: Figure S3.

\section{Inflammatory cytokine responses Bronchoalveolar lavage}

Significantly increased levels of IFN- $\gamma$, IL- 6 and TNF- $\alpha$ were observed in wildtype and TLR4-/- mice treated with LPS (Wildtype: IFN- $\gamma p=0.02$; IL-6 $p=0.002$; TNF- $\alpha p=0.001$, TLR4-/-: IFN- $\gamma p<0.001$; IL-6 $p<$ 0.001 ; TNF- $\alpha p<0.001$ ) and AMP- LPS (Wildtype: IFN$\gamma p<0.001$, IL-6 $p<0.001$, TNF- $\alpha p=0.001$, TLR4- $/-$ : IFN- $\gamma p<0.001$; IL-6 $p<0.001$; TNF- $\alpha p<0.001$ ), with

Table 1 Baseline lung function for mice studies completed in control and treated wildtype (WT) and TLR4 (TLR4 -/-) mutant mice. Baseline lung function measurements taken before methacholine challenge were not significantly different between treatments in WT and TLR4-/- mice. Greater Raw values were measured for all TLR4-/- mice compared to WT mice of the same treatment, indicating that overall, this mouse strain had more sensitive airways

\begin{tabular}{|c|c|c|c|c|c|c|c|c|}
\hline \multirow{2}{*}{$\begin{array}{l}\text { Treatment } \\
\text { Mouse strain }\end{array}$} & \multicolumn{2}{|c|}{ Control } & \multicolumn{2}{|l|}{$A M P$} & \multicolumn{2}{|l|}{ LPS } & \multicolumn{2}{|c|}{$A M P-L P S$} \\
\hline & $\overline{W T}$ & TLR4-/- & WT & TLR4-/- & WT & TLR4-/- & WT & TLR4-/- \\
\hline \multirow[t]{2}{*}{ Raw (hPa.s.ml ${ }^{-1}$ ) } & 0.35 & $0.45^{*}$ & 0.34 & $0.46^{*}$ & 0.34 & $0.40^{*}$ & 0.34 & $0.45^{*}$ \\
\hline & $(0.01)$ & $(0.02)$ & $(0.01)$ & $(0.02)$ & $(0.01)$ & $(0.03)$ & $(0.01)$ & $(0.02)$ \\
\hline
\end{tabular}

${ }^{*} p<0.05$ between WT and TLR4-/-,()indicates SD 


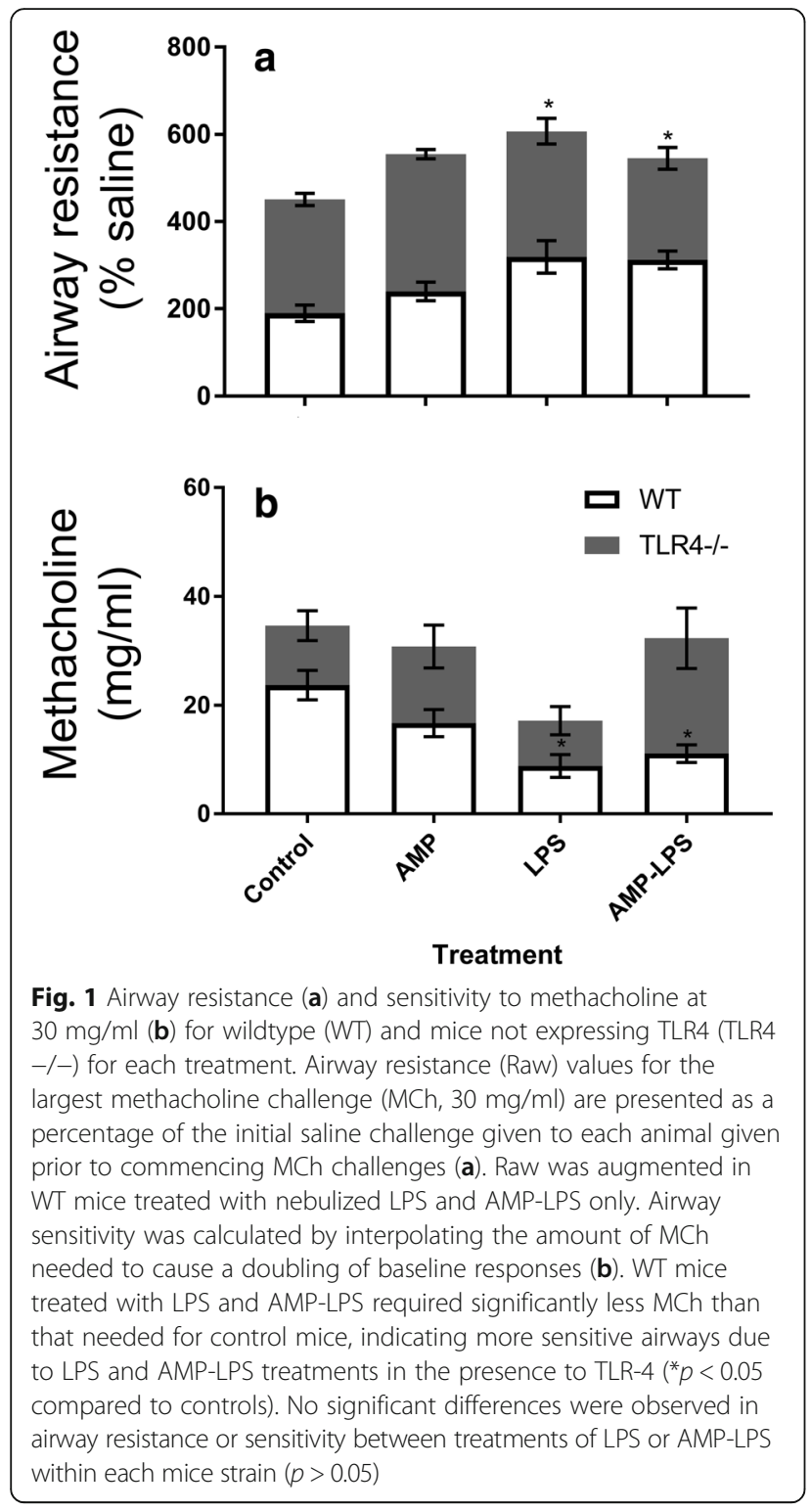

greater amount of cytokine in wildtype mice for these treatments (LPS $p=0.028$ and APM-LPS $p<0.001$ ) (Fig. 3). Only AMP-LPS treated TLR4-/- mice had significantly more TNF- $\alpha$ compared to LPS treated TLR4 $-/$ - mice $(p=0.032)$. The amounts of these cytokines were not significantly different in AMP treated mice compared to control mice for both strains.

\section{Lung parenchyma}

Soluble protein was extracted from one whole mouse lung lobe and analysed by ELISA for IL-10 and IL-13 expression showed no differences in these cytokines for any treatment in WT or TLR4-/- mice compared to controls $(p>0.05$ for all; Fig. 4). Similarly, there were no differences observed between WT and TLR4-/-

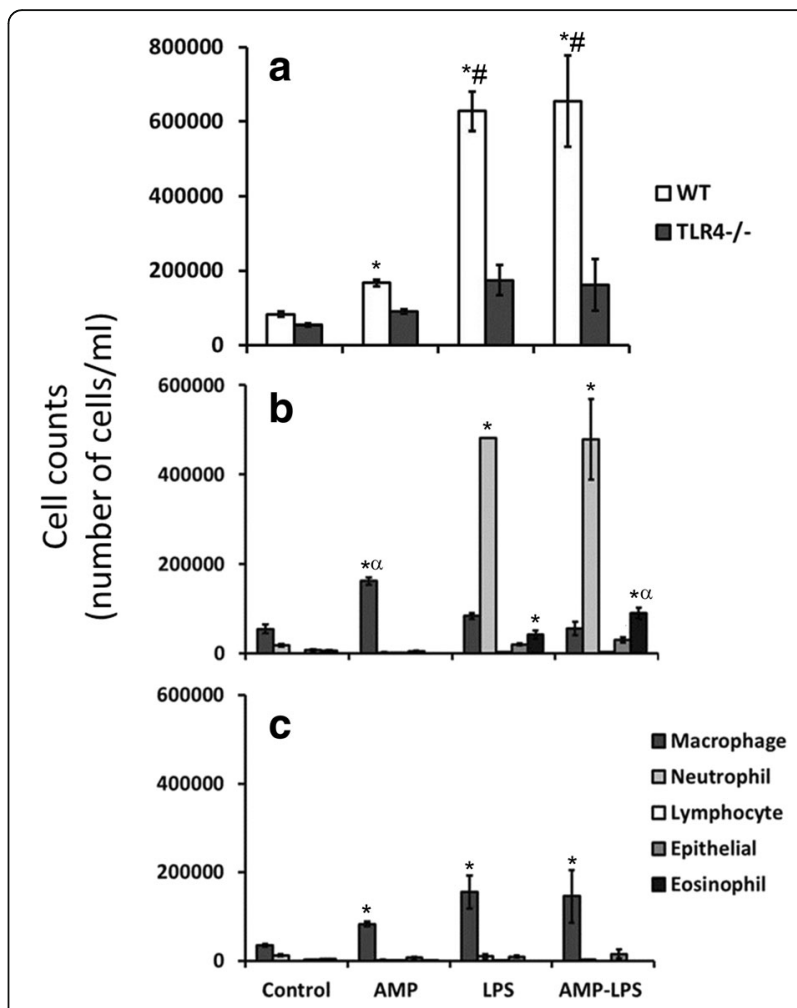

Fig. 2 Bronchoalveolar lavage (BAL) total (a) and differential cell counts (b, c) for wildtype (WT) and mice not expressing TLR4 (TLR4 $-/-)$ for each treatment. Elevated total cell counts in BAL were observed in WT mice treated with AMP, LPS and AMP-LPS compared to WT control mice. Cell counts in WT mice treated with LPS and AMP-LPS were also greater than similarly treated TLR4-/- mice. Neutrophils were the predominant cell type in LPS and AMP-LPS treated WT mice. Macrophages dominated counts in AMP treated WT and TLR4-/mice, as well as LPS and AMP-LPS treated TLR4-/- mice compared to respective controls. Greater eosinophil numbers were observed in WT mice treated with LPS and AMP-LPS; for which numbers were greater in AMP-LPS treated mice. Lymphocyte and epithelial cell numbers were not significantly different between controls and any of the treatments given for either strain $\left({ }^{*} p<0.05\right.$ between treatment and control; $\#=p<0.05$ between strains for the same treatment; $\mathbf{a}=p<0.05$ between treatment compared to all other treatments for the same strain)

mice for any of the individual inhaled treatments administered $(p>0.05)$.

\section{Discussion}

The results of this study clearly demonstrate that the inflammatory effects of inhaled particulate matter are heavily influenced by the presence of LPS. Airway resistance and sensitivity were shown to correlate inflammatory cytokine responses to inhaled LPS and AMP-LPS measured in bronchoavleolar lavage. While these responses were more pronounced when signalled by TLR-4, inflammation was also observed in TLR-4 knock-out mice indicating other LPS recognition pathways. A larger TNF- $\alpha$ response observed in TLR-4 knockout mice treated with AMP-LPS 


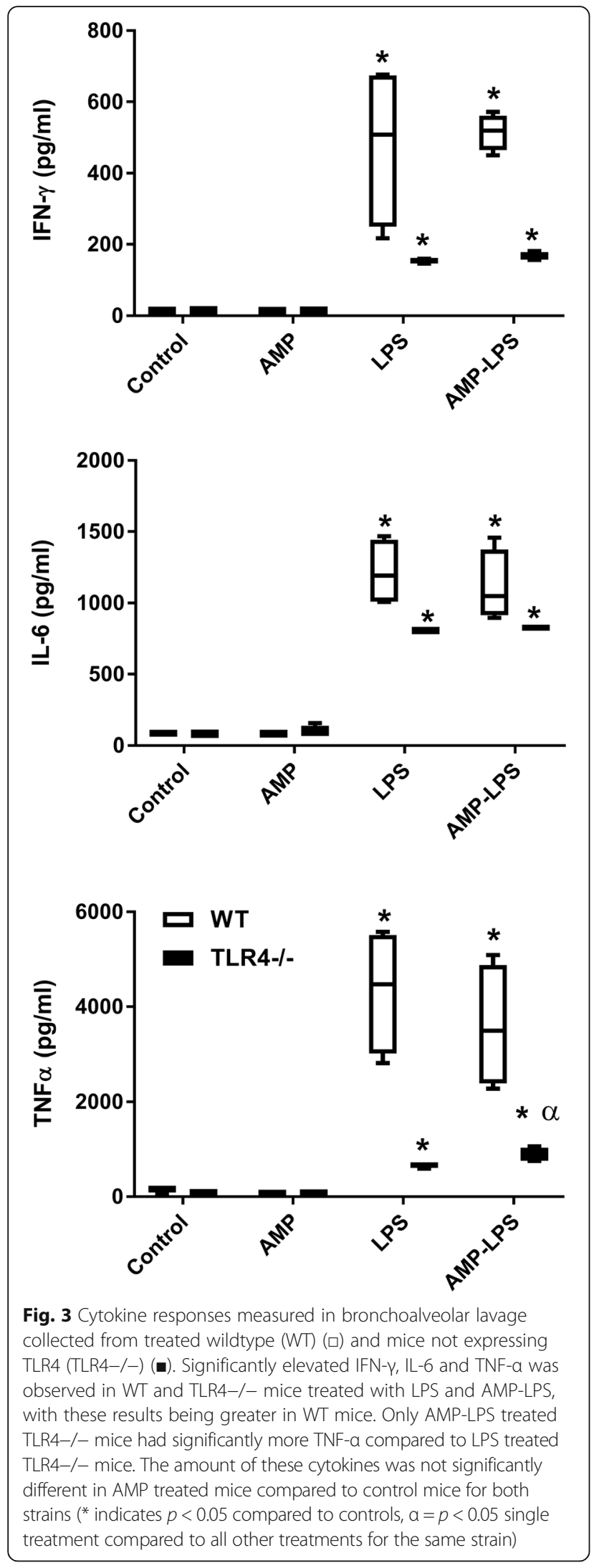

compared to LPS alone, suggest alternate recognition or a divergent signalling pathway for this treatment combination. As there were no changes observed in IL-10 or IL13 expression measured in lung parenchymal tissue, this suggests the inhaled preparations used in this study did not have an effect on airway tissue remodelling. Interestingly, elevated macrophage numbers observed in mice treated with inhaled latex beads alone, used as the model for AMP in this study, was not mimicked by increased inflammatory cytokine levels or augmented airway responses when compared to control non-treated mice.

Raised ambient PM levels are shown to be directly correlated to asthma admissions in health care centres, with long term exposure linked to the onset of lung cancer and COPD [2]. In this study, we did not find any significant change in lung function resulting from AMP exposure. However, augmented airway resistance and airway sensitivity responses to methacholine were observed in wildtype mice exposed to LPS and AMP-LPS. As LPS is found ubiquitously in the environment our data suggests LPS attached to inhalable AMP induces changes in lung function rather than AMP alone. As AMP exposure is linked to the onset of chronic diseases such as COPD, asthma and even cardiovascular disease a longer study period may be more suitable. This would allow tracking of slow onset of symptoms which underlie these diseases in response to ongoing long-term exposure to inhaled AMP.

Neutrophilic inflammation present in wildtype mice treated with LPS and AMP-LPS compared to TLR4-/mice indicates this response was driven by the presence of TLR-4 driven by the presence of LPS. In the absence of TLR-4, cellular inflammation to LPS and AMP-LPS was dominated by the presence of macrophages. AMP alone also induced increased macrophage infiltration compared to control mice, however this was observed irrespective of TLR-4 expression. Elevated macrophage numbers suggests either strengthened recruitment to the lung to clear inhaled particles, or impaired clearance, a hallmark of alveolar macrophages overloaded with phagocytosed particles [43-48]. On the other hand, larger neutrophil numbers in response to particle inhalation have been shown to correlate the onset of cancer tumors, an observation which dissipates when particle deposition shifts from the alveolar space to lung interstitium [49]. Airway deposition of AMP particles was not characterised in this study; however, these observations clearly demonstrate a greater number of macrophages with unchanged neutrophil numbers compared to nontreated control mice. Therefore, these findings suggest an interstitial lung deposition of AMP with induced inflammatory responses independent of TLR-4 expression for the first time. Interestingly, eosinophil numbers were significantly higher in wildtype mice treated with AMP- 

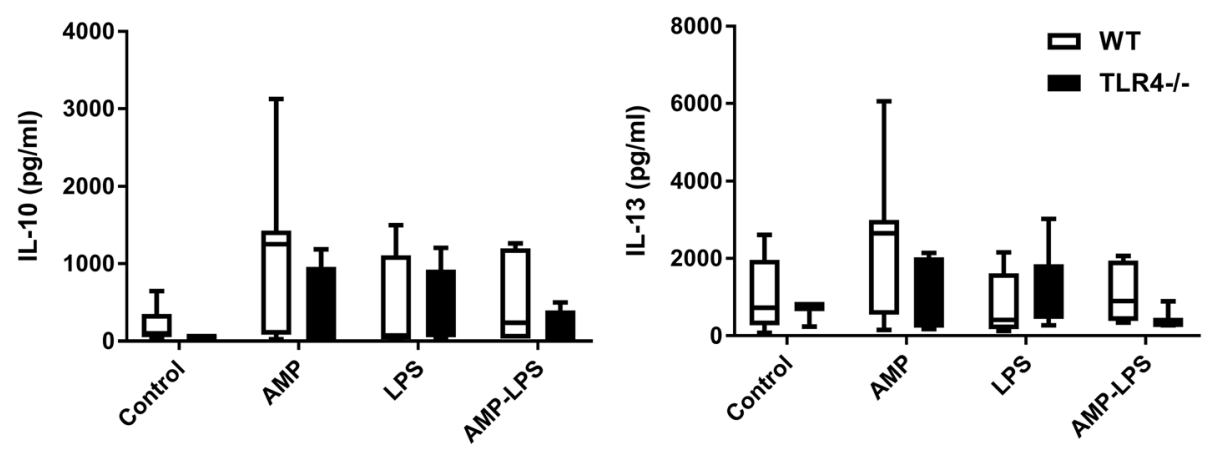

Fig. 4 Cytokines measured in lung parenchymal tissue from wildtype (WT) (ロ) and mice not expressing TLR4 (TLR4-/-) (घ) treated with AMP, LPS and AMP-LPS. There were no observed differences in IL-10 and IL-13 protein expression measured from whole mouse lung lobe analysed by ELISA for between mouse strains for any treatment or for any treatment compared to control non-treated mice $(p>0.05)$. Results were normalised to $100 \mu \mathrm{g}$ of total soluble protein for comparative purposes ( $n=$ minimum of 4 for each group)

LPS compared to LPS. Indeed distinct TLR-4 driven cellular compartments have been shown to activate neutrophilic and eosinophilic responses in response to different allergens [50], which may explain the larger eosinophil responses observed in wildtype mice treated with AMP-LPS compared to LPS alone. As eosinophilia is closely associated with the onset of asthma and allergy $[50,51]$, further investigation of this finding may elucidate the cellular mechanisms underlying allergic airway disease caused by exposure to particulates.

Of those treated wildtype mice, LPS or AMP-LPS induced the largest inflammatory cytokine responses measured in BAL. Augmented responses to LPS and AMP-LPS were also observed in TLR4-/- mice, illustrating proinflammatory signalling mechanisms other than TLR-4 activated by LPS. Furthermore, TNF- $\alpha$ levels were significantly greater in BAL of AMP-LPS treated TLR4-/mice compared to LPS treated mice, suggesting this combination was signalled by yet another mechanism. As we found evidence for LPS being attached to AMP, elevated TNF- $\alpha$ levels may have been induced by alternate receptors for LPS (such as scavenger receptors), or endocytosed resulting in recognition by intracellular pattern recognition receptors for LPS; including nucleotide-binding oligomerization domain (NOD) receptors contained in cellular inflammasomes [51]. Indeed, Shi et al. have shown binding of LPS by caspase 11 is critical for activation of this intracellular process [51]. Augmented TNF- $\alpha$ responses have been shown in the presence of eosinophilia $[52,53]$. Thereby the combination of elevated non-TLR4 driven TNF- $\alpha$ and TLR-4 driven eosinophilia observed in AMPLPS treated mice suggest AMP-LPS is a stronger stimulus for allergic inflammation in the airways than LPS alone. Despite a larger number of macrophages observed in AMP treated mice, these did not display inflammatory cytokine responses that were significantly different to those measured in non-treated control mice.
Interestingly, IL-10 or IL-13 measured in the lung parenchyma remained unchanged in response to all inhaled treatments for wildtype and TLR4-/- mice. This is surprising given the long-standing relationships between AMP exposure and airway disease development characterised by airway remodelling co-ordinated by these cytokines [54,55]. Within the context of this study, this novel finding suggests TLR-4 driven inflammatory responses activated by LPS recognition appear to be predominantly secreted (BAL). However, as long term-low grade inflammation activity can go undetected in subepithelial tissues for long periods [55], a larger study period may elucidate mechanisms pertinent to slow onset airway disease attributable to AMP exposure such as COPD and related cardiovascular disease [56]. Importantly, IL-13 responses are associated with allergen associated airway disease such as asthma [57]. Elevated TNF- $\alpha$ responses measured in BAL to LPS suggests modulation of this response by type- 2 inflammatory cytokines such as IL-4 or IL-5. Although closely affiliated with IL-4, IL-13 responses observed in lung parenchyma did not correlate LPS induced TNF- $\alpha$ responses in BAL [58]. Therefore, findings from a longer study period which include analysis of IL-4 or IL-5 may be valuable to our overall understanding of immune-modulated airway disease in response to allergic stimuli carried in inhaled air such as LPS, which has remained elusive to date [9].

\section{Conclusions}

In conclusion, we have shown the presence of LPS in AMP preparations has an influential impact on induced airway and inflammatory BAL responses in the lung which are augmented by the presence of TLR-4. Importantly, dominant macrophage responses observed in BAL from AMP treated mice over all other treatments, suggest interstitial lung deposition, triggered regardless of TLR-4 expression for the first time. Despite this, 
inflammatory cytokine responses were not observed in the lung parenchymal tissues in response to any treatment, suggesting a longer study period may be needed to observe pro-fibrotic changes that underlie airway disease caused by long-term AMP inhalation. Interestingly, when AMP was attached to LPS larger TNF- $\alpha$ responses independent of TLR-4 expression were observed in BAL suggesting activation of allergic responses by non-TLR4 pathways. If augmented by TLR-4 driven eosinophilia as observed in AMP-LPS treated mice, these findings suggest AMP-LPS as a stronger stimulus for allergic inflammation in the airways over LPS alone. Taken together, these results demonstrate divergent response pathways in the lung to AMP and LPS, with larger allergy affects observed in AMP-LPS which have not been shown before. Therefore, these findings contribute novel information to the field investigating the onset of allergic and non-allergic airway disease, such as asthma and COPD, as a result of PM exposure and warrants further investigation.

\section{Additional files}

Additional file 1: Figure S1. Airway resistance in TLR4-/- mice treated with double distilled water $\left(d_{d H_{2}} \mathrm{O}\right)$ and saline. Saline responses were significantly greater for methacholine challenges larger than $3 \mathrm{mg} /$ $\mathrm{ml}\left({ }^{*} p<0.05\right)$. (TIFF $356 \mathrm{~kb}$ )

Additional file 2: Figure S2. Airway resistance in wildtype (WT) and TLR4-/- mice for all treatment groups across for all methacholine challenges used. Raw was significantly greater in WT mice treated with LPS and AMP-LPS compared to control mice at $30 \mathrm{mg} / \mathrm{ml} \mathrm{MCh}$ $\left({ }^{*} p<0.05\right)$. (TIFF $1196 \mathrm{~kb}$ )

Additional file 3: Figure S3. Additional cytokines measured in bronchoalveolar lavage (BAL) and lung parenchyma. MCP-1 was measured in BAL using cytokine bead array assay (20-5000 pg/ml detection range) and IL-8 in lung parenchyma using ELISA (15.6-1000 pg/ml detection range) using optimised sample dilution factors. No significant difference with treatment was observed for these cytokines. (TIFF $558 \mathrm{~kb}$ )

\section{Acknowledgements}

None to declare

\section{Funding}

This work was supported by grants from the National Health and Medical Research Council of Australia and Princess Margaret Hospital for Children Foundation. Stephen M. Stick is a NHMRC Practitioner Fellow.

\section{Availability of data and materials}

The datasets used and/or analysed during the current study are available from the corresponding author on reasonable request.

\section{Authors' contributions \\ AMF, GZ, EMB and ENS performed the experiments and completed the analysis. AMF, AK, PSM, DAK, DJT and SMS conducted the data interpretation and manuscript preparation. AMF, PDS, DJT and SMS conceived the idea and designed the experiment. All authors read and approved the final manuscript}

\section{Ethics approval and consent to participate}

Mouse study approved by Telethon Kids Institute Animal Ethics Committee, approval reference number 128 .

\section{Consent for publication}

Not applicable, authors agree to pay journal processing fee should the manuscript be accepted for publication.

\section{Competing interests}

The authors declare that they have no competing interests.

\section{Publisher's Note}

Springer Nature remains neutral with regard to jurisdictional claims in published maps and institutional affiliations.

\section{Author details}

${ }^{1}$ School of Paediatrics and Child Health, University of Western Australia, Nedlands, WA, Australia. ${ }^{2}$ Telethon Kids Institute, Subiaco, WA, Australia. ${ }^{3}$ Department of Respiratory Medicine Princess Margaret Hospital for Children Perth, Subiaco, WA, Australia. ${ }^{4}$ Centre for Cell Therapy and Regenerative Medicine, School of Medicine and Pharmacology, The University of Western Australia, Nedlands, WA 6009, Australia. ${ }^{5}$ Department of Women's and Children's Health, Institute of Translational Medicine, University of Liverpool, Liverpool, UK. ${ }^{6}$ School of Biomedical Sciences and Pharmacy, University of Newcastle, Callaghan, NSW, Australia. ${ }^{7}$ Priority Research Centre for Asthma and Respiratory Disease, Hunter Medical Research Institute, Newcastle, NSW, Australia. ${ }^{8}$ Department of Anesthesiology, Pharmacology and Therapeutics, University of British Columbia, Vancouver, Canada. ${ }^{9}$ Queensland Children's Medical Research Institute, University of Queensland, Royal Children's Hospital, Herston, QLD, Australia.

Received: 1 September 2017 Accepted: 13 December 2017

Published online: 22 January 2018

\section{References}

1. Kelly FJ, Fussell JC. Air pollution and airway disease. Clin Exp Allergy. 2011; 41:1059-71

2. Pope CA 3rd, Dockery DW. Health effects of fine particulate air pollution: lines that connect. J Air Waste Manag Assoc. 2006:56:709-42.

3. Environmental Protection Agency U. National Ambient air Quality Standards for particulate matter; final rule, vol. 78. Research Triangle Park: National Archives and Records Administration: Federal Register; 2013. p. 103.

4. Guarnieri M, Balmes JR. Outdoor air pollution and asthma. Lancet. 2014;383: 1581-92.

5. Yeatts K, Svendsen E, Creason J, Alexis N, Herbst M, Scott J, Kupper L, Williams R, Neas L, Cascio W, et al. Coarse particulate matter (PM2.5-10) affects heart rate variability, blood lipids, and circulating eosinophils in adults with asthma. Environ Health Perspect. 2007;115:709-14.

6. Samet J, Krewski D. Health effects associated with exposure to ambient air pollution. J Toxicol Environ Health A. 2007;70:227-42.

7. Camatini M, Corvaja V, Pezzolato E, Mantecca P, Gualtieri M. PM10-biogenic fraction drives the seasonal variation of proinflammatory response in A549 cells. Environ Toxicol. 2012;27:63-73.

8. Gualtieri M, Ovrevik J, Holme JA, Perrone MG, Bolzacchini E, Schwarze $P E$, Camatini M. Differences in cytotoxicity versus pro-inflammatory potency of different PM fractions in human epithelial lung cells. Toxicol in Vitro. 2010;24:29-39.

9. Thomson EM, Vladisavljevic D, Mohottalage S, Kumarathasan P, Vincent R. Mapping acute systemic effects of inhaled particulate matter and ozone: multiorgan gene expression and glucocorticoid activity. Toxicol Sci. 2013;135:169-81.

10. Lippmann M, Chen LC, Gordon T, Ito K, Thurston GD. National particle component toxicity (NPACT) initiative: integrated epidemiologic and toxicologic studies of the health effects of particulate matter components. Res Rep Health Eff Inst. 2013;177:5-13.

11. HEl Review Panel on Ultrafine Particles. Understanding the health effects of ambient ultrafine particles. In: HEl perspectives, vol. 3. Boston: Health Effects Institute; 2013. p. 122.

12. HEl Review Panel on Ultrafine Particles. Understanding the health effects of ambient ultrafine particles. In: HEl perspectives, vol. 3. Boston: Health Effects Institute; 2013. p. 102.

13. Andersen ZJ, Wahlin P, Raaschou-Nielsen O, Ketzel M, Scheike T, Loft S. Size distribution and total number concentration of ultrafine and accumulation mode particles and hospital admissions in children and the elderly in Copenhagen, Denmark. Occup Environ Med. 2008;65:458-66. 
14. Pauluhn J. Inhalation toxicology: methodological and regulatory challenges. Exp Toxicol Pathol. 2008;60:111-24.

15. Pauluhn J. Derivation of occupational exposure levels (OELs) of low-toxicity isometric biopersistent particles: how can the kinetic lung overload paradigm be used for improved inhalation toxicity study design and OEL-derivation? Part Fibre Toxicol. 2014;11:72.

16. Oberdorster G. Pulmonary effects of inhaled ultrafine particles. Int Arch Occup Environ Health. 2001;74:1-8.

17. Brown DM, Stone V, Findlay P, MacNee W, Donaldson K. Increased inflammation and intracellular calcium caused by ultrafine carbon black is independent of transition metals or other soluble components. Occup Environ Med. 2000;57:685-91.

18. Donaldson K, Stone V, Seaton A, MacNee W. Ambient particle inhalation and the cardiovascular system: potential mechanisms. Environ Health Perspect. 2001;109(Suppl 4):523-7.

19. Li XY, Gilmour PS, Donaldson K, MacNee W. Free radical activity and proinflammatory effects of particulate air pollution (PM10) in vivo and in vitro. Thorax. 1996;51:1216-22.

20. Kerkhof M, Postma DS, Brunekreef B, Reijmerink NE, Wijga AH, de Jongste JC, Gehring U, Koppelman GH. Toll-like receptor 2 and 4 genes influence susceptibility to adverse effects of traffic-related air pollution on childhood asthma. Thorax. 2010;65:690-7.

21. Plummer LE, Ham W, Kleeman MJ, Wexler A, Pinkerton KE. Influence of season and location on pulmonary response to California's San Joaquin Valley airborne particulate matter. J Toxicol Environ Health A. 2012;75: 253-71.

22. Shoenfelt J, Mitkus RJ, Zeisler R, Spatz RO, Powell J, Fenton MJ, Squibb KA, Medvedev AE. Involvement of TLR2 and TLR4 in inflammatory immune responses induced by fine and coarse ambient air particulate matter. J Leukoc Biol. 2009:86:303-12.

23. Hirota JA, Hirota SA, Warner SM, Stefanowicz D, Shaheen F, Beck PL, Macdonald JA, Hackett TL, Sin DD, Van Eeden S, Knight DA. The airway epithelium nucleotide-binding domain and leucine-rich repeat protein 3 inflammasome is activated by urban particulate matter. J Allergy Clin Immunol. 2012;129:1116-25. e1116

24. Yamamoto M, Takeda K, Akira S. TIR domain-containing adaptors define the specificity of TLR signaling. Mol Immunol. 2004;40:861-8.

25. Finney SJ, Leaver SK, Evans TW, Burke-Gaffney A. Differences in lipopolysaccharide- and lipoteichoic acid-induced cytokine/chemokine expression. Intensive Care Med. 2012;38:324-32.

26. Becker S, Fenton MJ, Soukup JM. Involvement of microbial components and toll-like receptors 2 and 4 in cytokine responses to air pollution particles. Am J Respir Cell Mol Biol. 2002;27:611-8.

27. Eisenbarth SC, Piggott DA, Huleatt JW, Visintin I, Herrick CA, Bottomly K. Lipopolysaccharide-enhanced, toll-like receptor 4-dependent $T$ helper cell type 2 responses to inhaled antigen. J Exp Med. 2002;196:1645-51.

28. Morgan WJ, Crain EF, Gruchalla RS, O'Connor GT, Kattan M, Evans R 3rd, Stout J, Malindzak G, Smartt E, Plaut M, et al. Results of a home-based environmental intervention among urban children with asthma. N Engl J Med. 2004;351:1068-80.

29. Sawyer K, Mundandhara S, Ghio AJ, Madden MC. The effects of ambient particulate matter on human alveolar macrophage oxidative and inflammatory responses. J Toxicol Environ Health A. 2010;73:41-57.

30. Mirowsky J, Hickey C, Horton L, Blaustein M, Galdanes K, Peltier RE, Chillrud S, Chen LC, Ross J, Nadas A, et al. The effect of particle size, location and season on the toxicity of urban and rural particulate matter. Inhal Toxicol. 2013;25:747-57

31. Trosic I, Matausic-Pisl M, Hors N. Pathways and quantification of insoluble particles in the lung compartments of the rat. Int J Hyg Environ Health. 2000;203:39-43.

32. Poltorak A, He X, Smirnova I, Liu MY, Van Huffel C, Du X, Birdwell D, Alejos E, Silva M, Galanos C, et al. Defective LPS signaling in C3H/HeJ and C57BL/ 10ScCr mice: mutations in Tlr4 gene. Science. 1998;282:2085-8.

33. Musie E, Moore CC, Martin EN, Scheld WM. Toll-like receptor 4 stimulation before or after Streptococcus Pneumoniae induced sepsis improves survival and is dependent on T-cells. PLoS One. 2014;9:e86015.

34. Totemeyer S, Foster N, Kaiser P, Maskell DJ, Bryant CE. Toll-like receptor expression in $\mathrm{C} 3 \mathrm{H} / \mathrm{HeN}$ and $\mathrm{C} 3 \mathrm{H} / \mathrm{HeJ}$ mice during salmonella enterica serovar Typhimurium infection. Infect Immun. 2003;71:6653-7.

35. Happo MS, Salonen RO, Halinen Al, Jalava PI, Pennanen AS, Dormans JA, Gerlofs-Nijland ME, Cassee FR, Kosma VM, Sillanpaa M, et al. Inflammation and tissue damage in mouse lung by single and repeated dosing of urban air coarse and fine particles collected from six European cities. Inhal Toxicol. 2010;22:402-16.

36. Tulic MK, Knight DA, Holt PG, Sly PD. Lipopolysaccharide inhibits the latephase response to allergen by altering nitric oxide synthase activity and interleukin-10. Am J Respir Cell Mol Biol. 2001;24:640-6.

37. Carpenter M, Epperly MW, Agarwal A, Nie S, Hricisak L, Niu Y, Greenberger JS Inhalation delivery of manganese superoxide dismutase-plasmid/liposomes protects the murine lung from irradiation damage. Gene Ther. 2005;12:685-93.

38. Cannizzaro V, Berry LJ, Zosky GR, Turner DJ, Hantos Z, Sly PD. Impact of supplemental oxygen in mechanically ventilated adult and infant mice. Respir Physiol Neurobiol. 2009;165:61-6.

39. Zosky GR, Cannizzaro V, Hantos Z, Sly PD. Protective mechanical ventilation does not exacerbate lung function impairment or lung inflammation following influenza a infection. J Appl Physiol. 2009:107:1472-8.

40. Zosky GR, Larcombe AN, White OJ, Burchell JT, Janosi TZ, Hantos Z, Holt PG, Sly PD, Turner DJ. Ovalbumin-sensitized mice are good models for airway hyperresponsiveness but not acute physiological responses to allergen inhalation. Clin Exp Allergy. 2008;38:829-38.

41. Thamrin C, Janosi TZ, Collins RA, Sly PD, Hantos Z. Sensitivity analysis of respiratory parameter estimates in the constant-phase model. Ann Biomed Eng. 2004;32:815-22.

42. Becker S, Mundandhara S, Devlin RB, Madden M. Regulation of cytokine production in human alveolar macrophages and airway epithelial cells in response to ambient air pollution particles: further mechanistic studies. Toxicol Appl Pharmacol. 2005;207:269-75.

43. Oberdorster G, Ferin J, Morrow PE. Volumetric loading of alveolar macrophages (AM): a possible basis for diminished AM-mediated particle clearance. Exp Lung Res. 1992;18:87-104.

44. Nel AE, Madler L, Velegol D, Xia T, Hoek EM, Somasundaran P, Klaessig F, Castranova V, Thompson M. Understanding biophysicochemical interactions at the nano-bio interface. Nat Mater. 2009:8:543-57.

45. Warheit DB, Webb TR, Reed KL, Frerichs S, Sayes CM. Pulmonary toxicity study in rats with three forms of ultrafine-TiO2 particles: differential responses related to surface properties. Toxicology. 2007;230:90-104.

46. Dutta D, Sundaram SK, Teeguarden JG, Riley BJ, Fifield LS, Jacobs JM, Addleman SR, Kaysen GA, Moudgil BM, Weber TJ. Adsorbed proteins influence the biological activity and molecular targeting of nanomaterials. Toxicol Sci. 2007;100:303-15.

47. Haniu H, Saito N, Matsuda Y, Kim YA, Park KC, Tsukahara T, Usui Y, Aoki K, Shimizu M, Ogihara N, et al. Effect of dispersants of multi-walled carbon nanotubes on cellular uptake and biological responses. Int J Nanomedicine. 2011;6:3295-307.

48. Miyata R, van Eeden SF. The innate and adaptive immune response induced by alveolar macrophages exposed to ambient particulate matter. Toxicol Appl Pharmacol. 2011;257:209-26.

49. Greim H, Borm P, Schins R, Donaldson K, Driscoll K, Hartwig A, Kuempel E, Oberdorster G, Speit G. Toxicity of fibers and particles. Report of the workshop held in Munich, Germany, 26-27 October 2000. Inhal Toxicol. 2001;13:737-54.

50. McAlees JW, Whitehead GS, Harley IT, Cappelletti M, Rewerts CL, Holdcroft AM, Divanovic S, Wills-Karp M, Finkelman FD, Karp CL, Cook DN. Distinct Tlr4-expressing cell compartments control neutrophilic and eosinophilic airway inflammation. Mucosal Immunol. 2015;8:863-73.

51. Shi J, Zhao Y, Wang Y, Gao W, Ding J, Li P, Hu L, Shao F. Inflammatory caspases are innate immune receptors for intracellular LPS. Nature. 2014;514:187-92.

52. Ge XN, Ha SG, Greenberg YG, Rao A, Bastan I, Blidner AG, Rao SP, Rabinovich GA, Sriramarao P. Regulation of eosinophilia and allergic airway inflammation by the glycan-binding protein galectin-1. Proc Natl Acad Sci U S A. 2016;113:E4837-46.

53. Tonnel AB, Gosset $P$, Tillie-Leblond I. Characteristics of the inflammatory response in bronchial lavage fluids from patients with status asthmaticus. Int Arch Allergy Immunol. 2001;124:267-71.

54. Wilson MS, Elnekave E, Mentink-Kane MM, Hodges MG, Pesce JT, Ramalingam TR, Thompson RW, Kamanaka M, Flavell RA, Keane-Myers A, et al. IL-13Ralpha2 and IL-10 coordinately suppress airway inflammation, airway-hyperreactivity, and fibrosis in mice. J Clin Invest. 2007;117:2941-51.

55. Lee CG, Homer RJ, Cohn L, Link H, Jung S, Craft JE, Graham BS, Johnson TR, Elias JA. Transgenic overexpression of interleukin (IL)-10 in the lung causes mucus metaplasia, tissue inflammation, and airway remodeling via IL-13-dependent and -independent pathways. J Biol Chem. 2002;277:35466-74. 
56. Ling SH, van Eeden SF. Particulate matter air pollution exposure: role in the development and exacerbation of chronic obstructive pulmonary disease. Int J Chron Obstruct Pulmon Dis. 2009;4:233-43.

57. Murdoch JR, Lloyd CM. Chronic inflammation and asthma. Mutat Res. 2010; 690:24-39.

58. Li X, Howard TD, Zheng SL, Haselkorn T, Peters SP, Meyers DA, Bleecker ER. Genome-wide association study of asthma identifies RAD50-IL13 and HLA-DR/DQ regions. J Allergy Clin Immunol. 2010;125:328-35. e311 